\title{
Effect of Climate Change on Transformers Loading Conditions in the Future Smart Grid Environment
}

\author{
Murtaza Hashmi $^{1}$, Matti Lehtonen ${ }^{2}$, Seppo Hänninen ${ }^{1}$ \\ ${ }^{1}$ Energy Systems Knowledge Centre, VTT Technical Research Centre of Finland, Finland \\ ${ }^{2}$ Department of Electrical Engineering, Aalto University, Finland \\ Email: murtaza.hashmi@vtt.fi, matti.lehtonen@aalto.fi, Seppo.hanninen@vtt.fi
}

Received 2013

\begin{abstract}
The steady-state calculations are performed using IEC guidelines to determine the hot spot temperatures of distribution and power transformers in the worst projected Finnish environment due to long summer periods. Moreover, the effect of increase in winding resistance due to increase in ambient temperatures has been taken into account. The primary objective of the research is to investigate the possible extreme circumstances due to climate change. It is concluded that the power and distribution transformers should be progressively de-rated under such circumstances for their safe operations, which will not only prove cost-effective for utilities but also improve the reliability of the power supply to their valued customers in the challenging future smart grid environment.
\end{abstract}

Keywords: Distribution Transformer; Power Transformer; Winding Resistance; Climate Change; Electricity Distribution Company; Reliability; Smart Grid

\section{Introduction}

Power transformers are used in power generation units, transmission, and distribution networks to step up or down the voltage of the power system. The capacity is usually between a few MVA and about 100 MVA. To be able to use the real capacity of power transformers, it is important to know the duration and level to which power transformers can be thermally stressed. Because of increasing age coupled with higher loading and the need to more efficiently utilize expensive components such as transformers, increasing demands are being imposed on the liquid and solid insulating materials with regard to operating reliability and overloading capability.

The impact of large power transformer failure on power systems is due to their high cost, the impact on system operation due to their location and role in the network, and the fact that they are encased in tanks of flammable and toxic fluid, which is a potential risk to people, property and the environment [1]. These factors surely present a strong motivation for utilities to monitor the health of their power transformers. In short, power transformers are likely to be the most expensive asset within electrical networks [2], and so their availability and reliability is of paramount importance. Their nominal life expectancy is expressed in years, corresponding to their nameplate rated load and ideal conditions [3]. Failure will eventually occur as the paper insulation on the windings erodes and passes the limit where the structural and electrical stresses can be sustained. This unavoidable degradation is cumulative and is further increased by the presence of both heat and oil contaminants, including gases and water [4].

The designer aims to ensure that temperatures are kept to reasonable levels in a transformer when loaded up to continuous maximum rating. Practically, a power transformer has a significant thermal capacity largely arising from the insulating oil. This allows the possibility of loading for short periods beyond the continuous rated nameplate value [5]. Limitations on acceptable conductor and oil temperatures are typically stated in the transformer specification, and these in turn are likely to be based on recommendations in such documents as the international standard loading guide for oil immersed power transformers, IEC-354 [6].

A transformer's loading capacity is related to the exposure of its insulation to heat, the highest temperature of which is referred to as the hot spot temperature. The hot spot temperature effect on the paper insulation of winding is used to quantify the limit of its temperature range over a calculated period of time. The problem, however, is that these limits are dynamic due to the changing transformer characteristics and varying ambient climate conditions.

\section{Temperature Effects in Transformer}

When a current is passed through a conductor, heating 
losses are produced in the form of $i^{2} r$ losses, where $i$ is the magnitude of current passing through the conductor having resistance $r$. An equilibrium conductor temperature is reached if the heat can be removed at the same rate as that at which it is produced. Physical and chemical effects governing the interaction between materials are generally temperature-dependent and chemical reaction rates typically increase with increasing temperature [5].

Monitoring the transformers through temperature sensors is one of the simplest and most effective condition monitoring techniques for the asset management in smart distribution grid. Abnormal temperature readings almost always indicate some type of insulation failure in a transformer. For this reason, it has become common practice to monitor the hot spot, main tank, and bottom tank temperatures on the shell of a transformer. As the transformer begins to heat up, the winding insulation may start deteriorating and the value of the dielectric constant of the mineral oil reduces from the standard value.

According to the IEC guide, the ageing of the paper insulation system is such that the stated transformer life can be achieved for a continuous maximum hotspot temperature of $98^{\circ} \mathrm{C}$. Beyond this temperature, it is assumed that the rate of ageing doubles for every increase of $6^{\circ} \mathrm{C}$. At temperatures of the order of $150^{\circ} \mathrm{C}$, accelerated ageing tests in the laboratory demonstrate that the useful life of the paper may only be a few days. This clearly limits the life of the transformer and is one of the governing factors on the maximum load that should be used [5].

\section{Transformers Ratings Calculations}

Emergency and/or planned overloading of power transformers beyond their nameplate rating depends on several factors, including design and operating characteristics, daily load curve, historical loading data, testing and maintenance programs, and the particular applications. The overloading capabilities depend primarily on the winding hottest spot temperature. Determining accurately the hottest spot temperature is very critical to the transformer overall life expectancy assessment.

\subsection{IEC-354 Based Transformer Loading Guide}

Short duration and cyclic loadings are normally calculated following the principles in IEC-354. The loading guide tables are based solely on the equations for winding hotspot and oil temperatures, without regard for other factors. This is because the effects such as heating by stray losses are very dependent on design and in any case not easy to calculate. However, in constructing loading guide tables, the transformer user needs to be aware of restrictions on loading other than winding temperature and the circumstances in which those restrictions might apply [5].

The IEC standard provides a series of simplified equations that describe a mathematical model for the calculation of operating temperatures in a transformer. The assumptions listed in these standards include: a linear temperature rise in the oil from the bottom of the tank to the top, a parallel temperature rise in the windings, and an allowance for stray losses that is used to assess the hot spot temperature. As this standard points out for large power transformers, the results for hot spot temperatures (based on temperature rise tests) may not be valid due to the significance and complexity of the contribution of flux leakage to the heating of the windings. Therefore, this method has a limited use, restricted at or below the transformer's rated capacity. A further note in this standard adds that corrections to account for load losses and oil viscosity can be dismissed as either insignificant, or that the effects cancel each other.

A number of semi-empirical equations have been derived to predict the hottest spot temperature rise in transformers at their rated full load. Of these, the most common model used for this and top oil temperature calculations is described in IEC-354 [6]. A simplified transformer temperature distribution based on this model is shown in Figure 1 [7]. The steady state temperature relations in IEEE are similar to Figure 1, which have been extracted from the IEC loading guide [4].

\subsection{Different Temperatures in Transformer}

The ultimate hot spot temperature for a transformer under any load $K$ is equal to the sum of the ambient temperature, the top oil temperature rise over ambient, and the hot spot temperature rise over top oil. This can be expressed by the following well-known equation already used by many researchers.

$$
\theta_{H}=\theta_{A}+\Delta \theta_{T O}+\Delta \theta_{H}
$$

where $\theta_{A}$ is the ambient temperature in ${ }^{\circ} \mathrm{C}, \Delta \theta_{T 0}$ is the top oil temperature rise over ambient $\operatorname{in}^{\circ} \mathrm{C}, \Delta \theta_{H}$ is the hot

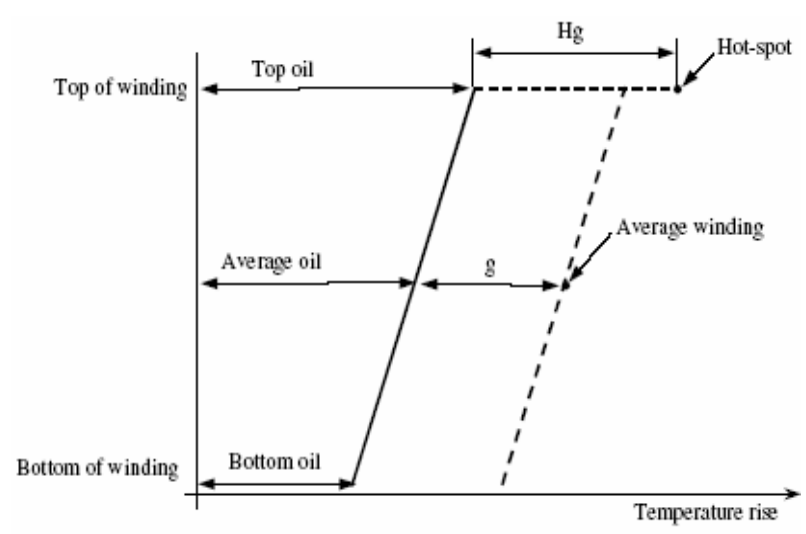

Figure 1. Transformer thermal diagram as per IEC-354 [7]. 
spot temperature rise over top oil temperature in ${ }^{\circ} \mathrm{C}$, and $\theta_{H}$ is the ultimate hot spot temperature in ${ }^{\circ} \mathrm{C}$. The top oil temperature over ambient temperature is given by the following equation:

$$
\Delta \theta_{T O}=\Delta \theta_{T O-R}\left(\frac{1+R \cdot K^{2}}{1+R}\right)^{n}
$$

where $\Delta \theta_{T O-R}$ is the top oil temperature rise over ambient at rated load, $R$ is the ratio of load losses at rated current to no load current losses, and $K$ is the load factor (supplied load/rated load). The hot spot temperature rise over top oil temperature is given by:

$$
\Delta \theta_{H}=H \cdot g \cdot K^{2 m}
$$

where $\Delta \theta_{H}$ is the hot spot to top oil rise, $H$ is the hot spot factor due to increased eddy losses at the winding end, and $g$ is the average winding to average oil temperature rise at rated load; $n$ and $m$ are empirically derived exponents that depends on the cooling method. The four modes of cooling used are: natural convection of oil in the transformer and natural convection of cooling air over the radiators (OA/ONAN), natural convection of oil with forced convection of air over the radiators (FA/ ONAF), non-directed forced oil flow and forced air flow (NDFOA/OFAF), and directed forced oil flow and forced air flow (DFOA/ODAF). The above mentioned exponents used are given in Table $\mathbf{1}$.

\subsection{Simplified Transformer Overloading Guide}

It is quite common practice to exceed the nameplate rating when loading power and distribution transformers for short times. Simplified transformer overloading guidelines take into consideration ambient temperature, nameplate rating, design fundamentals, long-time emergency loading, short-time overloading, moisture contents (every $0.5 \%$ increment of content reduces insulation life by half), etc.

Some of the key features are given for clarity and better understanding in [8-11], e.g. transformer hot spot temperatures above 98- cause the winding insulation to age faster. The rate at which transformer insulation deteriorates increases exponentially with temperature up to $140^{\circ} \mathrm{C}$; it doubles for every temperature rise of $6^{\circ} \mathrm{C}$. The

Table 1. Exponents used in temperature calculations.

\begin{tabular}{cccccc}
\hline \multirow{2}{*}{ Types of cooling } & \multicolumn{2}{c}{ IEC } & \multicolumn{2}{c}{ IEEE } \\
\cline { 2 - 5 } & $n$ & $m$ & $n$ & $m$ \\
\hline OA/ONAN & 0.9 & 0.8 & 0.8 & 0.8 \\
FA/ONAF & 0.9 & 0.8 & 0.9 & 0.8 \\
NDFOA/OFAF & 1 & 0.8 & 0.9 & 0.8 \\
DFOA/ODAF & 1 & 1 & 1 & 1 \\
\hline
\end{tabular}

insulation will rapidly deteriorate at temperatures above this level.

Notwithstanding, transformers can occasionally be run over their nameplate rating for a limited period, i.e. a few days, without dramatically reducing the life of the transformer. The relative rate of using life is given in [12]. If, e.g., a transformer is run at a continuous loading level that gives a winding temperature of $104^{\circ} \mathrm{C}$, the ageing rate would be doubled, i.e. the transformer will age two days in one day. If such periods are restricted to a few days and do not occur very often, the loss of life over its normal life span will be negligible. The converse is also true, periods of lower than $98^{\circ} \mathrm{C}$ operation will tend to "pay back" periods of moderate overloading. The number of hours per day of operation at any given value of winding hot spot temperature that will use one day's life are also given in [12]. A winding hot spot of $116^{\circ} \mathrm{C}$ that prevails for three hours would produce ageing equivalent to one day according to this modeling. In general, the application of load in excess of nameplate rating involves a degree of risk and accelerated aging. These effects (short term transformer failure, under overloading conditions, and long duration overload) are summarized in [13].

\subsection{Transformer Loading in "Worst" Finnish Environment}

The ambient temperature plays an important role for the determination of the hot spot temperature of a transformer determined by its loading profile. The hot spot temperature increases linearly by increasing the ambient temperature. Roughly, for every $1{ }^{\circ} \mathrm{C}$ increment in ambient temperature, the loading capacity can be decreased by $1 \%$ without any loss-of-life and vice versa.

On average, the ambient temperature is increasing to some extent every year due to the effect of overall global warming. This has been realized by monitoring ambient temperatures over the last several years. The IEC loading guide is recommended for transformers operating with an ambient temperature of $20^{\circ} \mathrm{C}$. However, it does not give the actual hot spot temperature at varying ambient temperatures. Table 2 gives the future ambient temperatures of different locations in Finland which is based on weather forecasts [14]. It is revealed that ambient temperature may increase up to $33.8^{\circ} \mathrm{C}$ in Helsinki during the years $2016-2045$.

\section{Hot Spot Temperatures Calculations}

In this paper, steady-state calculations are performed to calculate the hot spot temperature of distribution and power transformers for possible future ambient temperatures in Finland varying from $20-40^{\circ} \mathrm{C}$. The value of $g$ in the calculations is assumed to be $23^{\circ} \mathrm{C}$. The value of $H$ is 
Table 2. Extreme temperatures for the periods 1961 - 1990 and 2016 - 2045 (ilmatieteen laitos 1991).

\begin{tabular}{ccccc}
\hline & \multicolumn{4}{c}{ Extreme temperatures $\left({ }^{\circ} \mathrm{C}\right)$} \\
\cline { 2 - 5 } & 1961 & 1990 & 2016 & 2045 \\
\hline Helsinki & -35.9 & 31.9 & -28.4 & 33.8 \\
Tampere & -37 & 31.6 & -30 & 33.5 \\
Vaasa & -38.6 & 31.8 & -31.6 & 33.7 \\
Kuopio & -39.3 & 32.6 & -32.6 & 34.6 \\
Kuusamo & -45.2 & 31.2 & -39.2 & 33.1 \\
Sodankylä & -44.7 & 31.3 & -38.8 & 32.9 \\
\hline
\end{tabular}

assumed to be 1.1 for distribution transformers and 1.3 for medium size and large power transformers. The value of $\Delta \theta_{T O-R}$ is selected in such a fashion $\left(57.8^{\circ} \mathrm{C}\right.$ for distribution transformers and $54.1^{\circ} \mathrm{C}$ for power transformers) that the ultimate hot spot temperature works out to be 98 ${ }^{\circ} \mathrm{C}$ for an ambient temperature of $20^{\circ} \mathrm{C}$. A $500 \mathrm{kVA}$ transformer having load losses of $5 \mathrm{~kW}$ at ambient temperature $20^{\circ} \mathrm{C}$ and a $20 \mathrm{MVA}$ transformer having load losses of $106 \mathrm{~kW}$ at ambient temperature $20^{\circ} \mathrm{C}$ are considered for calculations.

\subsection{Calculations for Distribution Transformers}

The data for secondary line transformers is given in Appendix 1 [15]. The values of $n$ and $m$ are taken as 0.9 and 0.8 , respectively, for the ONAN mode of cooling. $R$ is defined as the ratio between load losses at rated current to no load losses. The load losses at rated current given by the manufacturer are estimated at an ambient temperature of $20^{\circ} \mathrm{C}$. However, their value increases due to increase in the resistance of the windings at higher ambient temperatures. A $0.4 \%$ increase in load losses due to a $1{ }^{\circ} \mathrm{C}$ rise in ambient temperature is a good approximation for this calculation. The load losses at rated current (given in Appendix 1) also include this incremental factor. For example, the load losses at rated current for a 50 $\mathrm{kVA}$ transformer are given as $1330 \mathrm{~W}$ at an ambient temperature of $20^{\circ} \mathrm{C}$ [15]. The hot spot temperature is to be calculated at $33.8^{\circ} \mathrm{C}$ (the projected maximum temperature in Helsinki in 2045). The increase in ambient temperature is $13.8^{\circ} \mathrm{C}$, which increases the load losses by $73 \mathrm{~W}$. Therefore, the total load losses are estimated to be $1403 \mathrm{~W}$. The value of $R$ is recalculated due to the increase in load losses. The rated load of the transformer slightly increases due to increases in load losses (temperature dependent) at higher ambient temperatures; therefore, the supplied load is also increased to the same extent for unity load factor conditions $(K=1)$. For determining the actual de-rating factor of the transformers, the calculated value (including the effect of temperature dependent load losses) is divided by the same incremental factor.

The hot spot temperature for an ambient temperature of $33.8^{\circ} \mathrm{C}$ (Helsinki maximum future temperature in 2045 ) is calculated to be $115^{\circ} \mathrm{C}$ for a variety of distribution transformers. Conversely, the transformers should be de-rated to approximately $86 \%-87 \%$ of their maximum load for a hot spot temperature of $98^{\circ} \mathrm{C}$ (as per IEC guide). The value of the hot spot temperature is approximately the same for different ratings of transformers. The ratings of the transformers do not have significant effect on the load factor, i.e. the de-rated values of load factors for distribution transformers are in the same range.

\subsection{Calculations for Power Transformers}

The data for primary line transformers is given in Appendix 2 [15]. The assumptions stated in sub-section 4.1 have also been implemented in the calculations for power transformers. The load losses at rated current (given in Appendix 2) also include the incremental factor explained in sub-section 4.1. For example, the load losses at rated current for a 16 MVA transformer are given as $88 \mathrm{~kW}$ at an ambient temperature of $20^{\circ} \mathrm{C}$ [13]. The hot spot temperature is to be calculated at $33.8^{\circ} \mathrm{C}$ (Helsinki maximum future temperature in 2045). The increase in ambient temperature is $13.8^{\circ} \mathrm{C}$ which increases the load losses by $4.9 \mathrm{~kW}$, and so the total load losses are estimated to $92.9 \mathrm{~kW}$.

The hot spot temperature for an ambient temperature of $33.8^{\circ} \mathrm{C}$ (Helsinki's maximum future temperature in 2045) is calculated to be $115^{\circ} \mathrm{C}$. Conversely, the transformers should be de-rated to approximately $86 \%$ - $87 \%$ of their maximum load to maintain a hot spot temperature of $98^{\circ} \mathrm{C}$ (as per IEC guide). The value of the hot spot temperature is approximately the same for different ratings of transformers. The ratings of the transformers do not have a significant effect on the load factor, i.e. the derated values of load factors for power transformers are in the same range. The different values of hot spot temperatures and load factors due to variation in ambient temperature are calculated for distribution and power transformers and are given in Table 3.

\section{Results and Discussion}

The results are extracted from the hot spot temperatures calculations performed in the previous section. It is revealed from Figure 2 that by increasing the ambient temperature, the hot spot temperature also increases. This relationship is not quite linear because the temperature dependent winding resistance effects have been taken into account. The rated load losses depend on ambient temperature and this has been considered during the calculations. The effect of ambient temperature on the rating 
of transformers (load factor) is depicted in Figure 3, which highlights the fact that transformers must be derated to avoid excessive ageing and loss-of-life.

Table 3. Hot spot and load factor values at various ambient temperatures for distribution and power transformers.

\begin{tabular}{ccccc}
\hline & \multicolumn{2}{c}{ Distirbution transformer } & \multicolumn{2}{c}{ Power transformer } \\
\cline { 2 - 5 }$\theta_{A}$ & $\begin{array}{c}\theta_{H}(\text { for } \\
K=1)\end{array}$ & $\begin{array}{c}K\left(\text { for } \theta_{H}\right. \\
\left.=98^{\circ} \mathrm{C}\right)\end{array}$ & $\begin{array}{c}\theta_{H}(\text { for } \\
K=1)\end{array}$ & $\begin{array}{c}K\left(\text { for } \theta_{H}\right. \\
\left.=98^{\circ} \mathrm{C}\right)\end{array}$ \\
\hline 20 & 98 & 1 & 98 & 1 \\
22 & 100.5 & 0.981 & 100.5 & 0.98 \\
24 & 103.1 & 0.961 & 103.1 & 0.962 \\
26 & 105.6 & 0.94 & 105.6 & 0.942 \\
28 & 108.1 & 0.921 & 108.1 & 0.923 \\
30 & 110.6 & 0.901 & 110.7 & 0.904 \\
32 & 113.1 & 0.881 & 113.2 & 0.884 \\
34 & 115.6 & 0.861 & 115.7 & 0.865 \\
36 & 118.2 & 0.841 & 118.2 & 0.845 \\
38 & 120.7 & 0.821 & 120.8 & 0.824 \\
40 & 123.2 & 0.8 & 123.3 & 0.805 \\
\hline
\end{tabular}

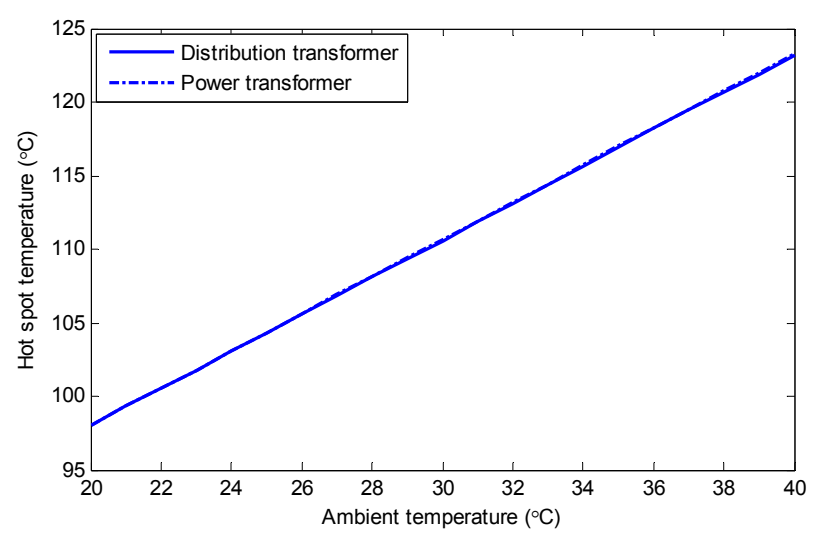

Figure 2. Effect of ambient temperature on hot spot temperature for distribution and power transformers.

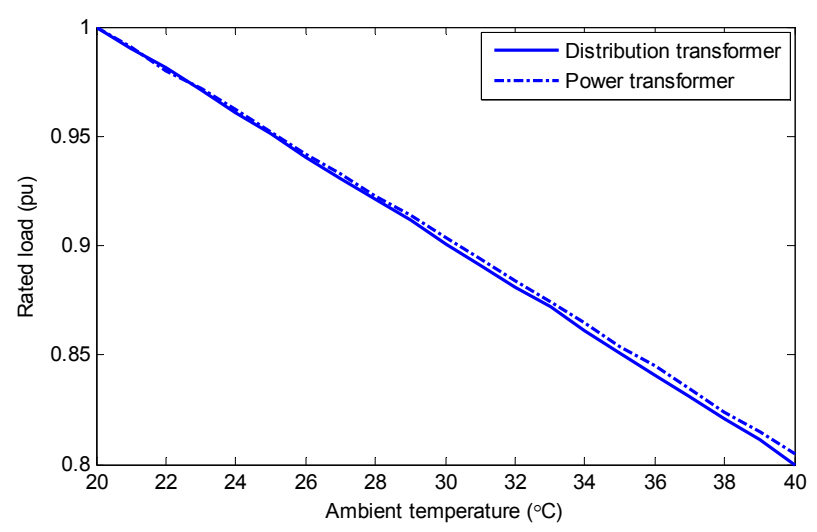

Figure 3. Effect of ambient temperature on load factor for distribution and power transformers.
It is proposed that power transformers should be de-rated to a greater extent than distribution transformers (please see Figure 2, where the hot spot temperatures of power transformers seem slightly higher than distribution transformers). However, this fact is not revealed in Figure 3 due to different values of $R$ for distribution and power transformers used in the calculations; the available data does not cover a variety of ratings. Moreover, the same values of $m$ and $n$ have been used for distribution and power transformers, but these values should be different in a more comprehensive analysis. For example, considering the DFOA/ODAF mode of cooling for power transformers $(n=1$ and $m=1)$ at the same ambient temperature, the hot spot temperature would rise higher than in a distribution transformer, while it would be de-rated to a lower extent than a distribution transformer. The difference in hot spot temperatures and rated loads of distribution and power transformers at extreme temperature $\left(40^{\circ} \mathrm{C}\right)$ in Figure 2 and Figure 3 are only $0.08 \%$ and $0.6 \%$, respectively, which may increase by changing the mode of cooling for power transformers.

\section{Conclusions}

Hot spot temperature calculations for the projected future ambient temperature are performed using IEC guide. The hot spot temperature increases almost linearly by increasing the ambient temperature. Conversely, the transformers should be de-rated from their given loading values (provided by the manufacturers).

The hot spot temperature of distribution and power transformers may increase up to $115^{\circ} \mathrm{C}$ in Helsinki (due to increase in ambient temperature up to $33.8^{\circ} \mathrm{C}$ ), therefore, the transformers must be progressively de-rated to $86 \%-87 \%$ of their actual ratings without loss-of-life. If hot spot temperatures increase up to $115^{\circ} \mathrm{C}$, the relative rate of using life of transformers may decrease up to 8 times if operated continuously.

To prevent transformers from early ageing, they should only be operated less than 3 hours per day in this worst environmental condition as stated above. This study will be useful for electric power utilities to revise the allowable loadings of their transformers to avoid damage, as well as for the safe and reliable distribution of power to their valued customers. The investigation carried out will be helpful to analyze for how long the new distribution and power transformers installations can be partially delayed and how better and reliable asset management can be carried out in the challenging future smart grid environment.

\section{REFERENCES}

[1] J. L. Kirtley, Jr., et al., "Monitoring the Health of Power Transformers," IEEE Computer Applications in Power, 
1996, pp. 18-23.

[2] O. Roizman and V. Davydov, "Neuro-Fuzzy Computing for Large Power Transformers Monitoring and Diagnostics," 18th International Conference of the North American (Fuzzy Information Processing Society, 1999, pp. 248-252.

[3] V. Ohis and T. Czaszejko, "Techniques for Estimation of Hot Spot Temperature in Transformers," Australian Universities Power Engineering Conference (AUPEC02), Melbourne, Australia, Sept-Oct, 2002.

[4] IEEE Std. C57.91-1995 "IEEE Guide for Loading Mineral-Oil-Immersed Transformers".

[5] E. Simonson, "Transformer Ratings and Transformer Life," IEE Colloquium on Transformer Life Management, London, UK, October 1998.

[6] IEC 354 1991-09 "Loading Guide for Oil-Immersed Power Transformers".

[7] A. A. Elmoudi, "Evaluation of Power System Harmonic Effects on Transformers," PhD dissertation at Helsinki University of Technology (TKK), Espoo, 2006.

[8] P. K. Sen, “Transformer Overloading," International Journal of Power and Energy Systems, Vol. 19, No. 1, 1999, pp. 55-59.
[9] L. W. Pierce, "Predicting Liquid Filled Transformer Loading Capability," IEEE Transactions on Industry Applications, Vol. 33, No. 1, January 1994, pp. 170-178.

[10] L. W. Pierce, "An Investigation of the Thermal Performance of an Oil Filled Transformer Winding," IEEE Transactions on Power Delivery, Vol. 7, No. 3, July 1992, pp. 1347-1358.

[11] P. K. Sen and S. Pansuwan, "Overloading and Loss-of-Life Assessment Guidelines of Air-cooled Transformers," Proceedings of Rural Electric Power Conference, Little Rock, AR, USA, April-May 2001.

[12] D. Harrison, "Loading capabilities of large power transformers," Power Engineering Journal, October 1995, pp. 225-230.

[13] R. Chenier and J. Aubin, "Econimic Benifit and Risk Evaluation of Power Transformer Overloading," IEEE Power Engineering Society Winter Meeting 2001, Columbus, USA, Vol. 2, 2001, pp. 459-462.

[14] A. Martikaine, "IImastonmuutoksen vaikutus sähköverkkliiketoimintaan" VTT TIEDOTTEITA 2338, Espoo 2006.

[15] Teknisiä Tietoja ja Taulukoita, TT

Appendix 1. Hot spot temperature calculations at extreme temperature $\left(33.8^{\circ} \mathrm{C}\right)$ for distribution transformers.

\begin{tabular}{cccccccccc}
\hline $\begin{array}{c}\text { Rating } \\
(\mathrm{kVA})\end{array}$ & $\begin{array}{c}\text { Voltage level } \\
(\mathrm{kV} / \mathrm{kV})\end{array}$ & $\begin{array}{c}\text { Mode of } \\
\text { cooling }\end{array}$ & $\begin{array}{c}\text { No load } \\
\text { losses }(\mathrm{W})\end{array}$ & $\begin{array}{c}\text { Load losses at rated } \\
\text { current }(\mathrm{W})\end{array}$ & $R$ & $\Delta \theta_{T 0}$ & $\Delta \theta_{H}$ & $\theta_{H}$ (for $\left.K=1\right)$ & $K\left(\right.$ for $\left.\theta_{H}=98^{\circ} \mathrm{C}\right)$ \\
\hline 50 & $20 / 0.4$ & ONAN & 150 & 1403 & 9.3 & 60.4 & 21.3 & 115.5 & 0.868 \\
100 & $20 / 0.4$ & ONAN & 245 & 1973 & 8 & 60.3 & 21.3 & 115.5 & 0.867 \\
200 & $20 / 0.4$ & ONAN & 465 & 2743 & 5.9 & 60.2 & 21.3 & 115.4 & 0.864 \\
500 & $20 / 0.4$ & ONAN & 930 & 5276 & 5.7 & 60.2 & 21.3 & 115.4 & 0.863 \\
1000 & $20 / 0.4$ & ONAN & 1500 & 8864 & 5.9 & 60.2 & 21.3 & 115.4 & 0.864 \\
\hline
\end{tabular}

Appendix 2. Hot spot temperature calculations at extreme temperature $\left(33.8^{\circ} \mathrm{C}\right)$ for power transformers.

\begin{tabular}{|c|c|c|c|c|c|c|c|c|c|}
\hline Core & $\begin{array}{l}\text { Rating } \\
\text { (MVA) }\end{array}$ & $\begin{array}{l}\text { Mode of } \\
\text { cooling }\end{array}$ & $\begin{array}{c}\text { No load } \\
\text { losses }(\mathrm{kW})\end{array}$ & $\begin{array}{l}\text { Load losses at } \\
\text { rated current }(\mathrm{kW})\end{array}$ & $R$ & $\Delta \theta_{T 0}$ & $\Delta \theta_{H}$ & $\theta_{H}($ for $K=1)$ & $K\left(\right.$ for $\left.\theta_{H}=98^{\circ} \mathrm{C}\right)$ \\
\hline $\mathrm{Cu}$ & 20 & ONAN & 16.8 & 111.8 & 6.6 & 56.4 & 25.2 & 115.5 & 0.867 \\
\hline $\mathrm{Cu}$ & 31.5 & ONAN/ONAF & 24.5 & 143.5 & 5.8 & 56.4 & 25.2 & 115.4 & 0.865 \\
\hline $\mathrm{Al}$ & 40 & ONAN/ONAF & 33.5 & 187.8 & 5.6 & 56.4 & 25.2 & 115.4 & 0.865 \\
\hline
\end{tabular}

